\title{
Reformas a los mecanismos de colaboración administrativa a propósito de los diez años de vigencia de la ley 27444
}

\section{Reforms of administrative cooperation mechanisms with regard to the ten year life of the Law 27444}

\section{RICHARD J. MARTIN TIRADO*}

Resumen: Desde la entrada en vigencia de la Ley del Procedimiento Administrativo General (en adelante, LPGA,) y en correspondencia con el principio de unidad de la actuación de la administración pública en su conjunto, existe una regla general de colaboración y cooperación entre las entidades que la conforman, con lo que se deja de lado la idea de que solo era posible una interrelación conflictual entre ellas. La colaboración administrativa debe ser apreciada como una noción general en el Derecho administrativo, que trasciende a la cooperación entre entidades públicas, por lo que se torna ineludible dejar atrás el criterio de aplicación restrictivo contenido en la actual normativa. De este modo, el presente artículo - tras analizar aquellas disposiciones de la LPAG que regulan el tema planteado y tomando en cuenta el nuevo rol que vienen asumiendo las entidades públicas en sus relaciones con terceros- pone de relieve la necesidad de un nuevo enfoque de la colaboración administrativa, lo que precisa las modalidades, características y técnicas requeridas para poner en práctica eficientemente esta figura.

Palabras clave: Colaboración administrativa - entidades públicas - Ley del Procedimiento Administrativo General - principio de unidad de la actuación de la administración pública

Abstract: Since the General Administrative Procedure Law (hereinafter LPGA) entry into force, and according to Public Administration Performance Principle of Unity as a whole, there is a collaboration and cooperation general rule between entities involved, setting aside the idea that only a confrontational interrelationship between them is possible. Administrative collaboration must be appreciated as a general concept on Administrative Law, this goes beyond cooperation among public entities, becoming essential to leave behind restrictive application criteria contained in current regulations. Thus, after analyzing those LPAG regulation provisions on this issue, and considering public entities new role on their relationships with third parties, this article emphasizes the need of a new administrative collaboration approach, specifying types, characteristics and techniques required to efficiently implement this concept.

Key words: Administrative collaboration - Public entities - General Administrative Procedure Law - Public Administration Performance Principle of Unity

* Es abogado por la Pontificia Universidad Católica del Perú, máster en Administración Pública por el Instituto Universitario de Investigación Ortega y Gasset adscrito a la Universidad Complutense de Madrid. Realizó una maestría en Derecho internacional económico por la Pontificia Universidad Católica del Perú. Se desempeña como profesor en la Pontificia Universidad Católica del Perú, en la Universidad de Lima, en la Universidad ESAN y en la Universidad San Ignacio de Loyola. 
CONTENIDO: INTRODUCCIÓN. - I. LA COLABORACIÓN ADMINISTRATIVA EN LA LEY DEL PROCEDIMIENTO ADMINISTRATIVO GENERAL. - I.1. ANÁLISIS DEL ARTÍCULO 76 DE LA LPAG. - I.2. ANÁLISIS DEL ARTÍCULO 77 DE LA LPAG. I.3. ANÁLISIS DEL ARTÍCULO 78 DE LA LPAG. - I.4. ANÁLISIS DEL ARTÍCULO 79 DE LA LPAG. - II. LA NECESIDAD DE UN NUEVO ENFOQUE DE LA COLABORACIÓN ADMINISTRATIVA. - II.1. UN FENÓMENO GENERAL. - II.2. MODALIDADES DE COLABORACIÓN ADMINISTRATIVA. - II.2.1. ENTRE ENTIDADES PÚBLICAS Y PRIVADAS. - II.2.2. ENTRE PARTICULARES. - II.3. CARACTERÍSTICAS. II.3.1. SUSTANCIAL. - II.3.2. PROCESAL. - III. LA NECESIDAD DE ACTUALIZAR LAS REGLAS VIGENTES. - IV. CONCLUSIONES.

\section{INTRODUCCIÓN}

La Ley del Procedimiento Administrativo General (ley 27444) regula un aspecto de la colaboración administrativa en las disposiciones del subcapítulo III del capítulo II del título II, denominando «Colaboración entre entidades».

Este marco legal inspiró hace algunos años un trabajo del autor que fue materia de una ponencia en el Segundo Congreso de Derecho Administrativo organizado por la Asociación Peruana de Derecho Administrativo. En dicho trabajo, se estudió el tema de las técnicas administrativas de descentralización y desconcentración, y las ventajas que ofrece a estos procesos la celebración de convenios de colaboración administrativa.

En dicha oportunidad — hace poco más de cinco años- era necesario evaluar desde una perspectiva general qué era la descentralización y cómo se descentralizaba, para posteriormente analizar un aspecto de la colaboración administrativa, definido por la LPAG como «colaboración entre entidades» y la «celebración de convenios de colaboración administrativa».

Sin embargo, hoy en día y a casi diez años de vigencia de la LPAG, es importante tener en cuenta que el campo de la colaboración administrativa no solo se reduce a la celebración de convenios de colaboración o que estos solo se podrían celebrar para coadyuvar a los procesos de descentralización. Es decir, resulta imprescindible ampliar el panorama de la colaboración administrativa y comprender esta figura jurídica como una noción general en el Derecho administrativo, que trasciende a la colaboración entre entidades y a la celebración de convenios de colaboración, tal como se explicará en el presente artículo. 


\section{LA COLABORACIÓN ADMINISTRATIVA EN LA LEY DEL PROCEDIMIENTO ADMINISTRATIVO GENERAL}

En términos generales, los artículos 76 al 79 de la LPAG, modificados por el decreto legislativo 1029 del pasado 24 de junio de 2008, regulan en el marco del procedimiento administrativo, el deber de colaboración administrativa que deben brindarse entre sí las entidades que forman parte de la administración pública.

Tal como se ha señalado en un trabajo anterior ${ }^{1}$, los preceptos normativos señalados, más allá de establecer el principio de colaboración institucional entre las entidades de la administración pública, ofrecen nuevas perspectivas para la interrelación entre entidades, distintas a la conflictual $^{2}$ o de la contienda de competencias que usualmente caracteriza a la relación entre entidades públicas.

En este sentido, la LPAG, que buscaba unificar la dispersión normativa existente hasta antes de su dación, aporta a nuestro ordenamiento jurídico el principio de la unidad de la actuación de la administración pública en su conjunto. Por ello, las entidades descritas en el artículo I del título preliminar de la LPAG y que conforman la administración pública ${ }^{3}$ se encuentran obligadas a coordinar, cooperar y colaborar entre sí, a fin de evitar la duplicidad de funciones, la dispersión normativa y de cumplir adecuadamente sus funciones.

De este modo, se puede afirmar que el principio de colaboración entre entidades y de unidad de la actuación de la administración pública en su conjunto tienen como finalidad lograr la coherencia de la actuación del conjunto de las entidades integrantes de la administración pública y evitar así que luego de la distribución funcional entre estas entidades se produzca lo que Santamaría Pastor ${ }^{4}$ denomina una descoordinada actuación:

1 MARTIN TIRADO, Richard. "Tutela sectorial, desconcentración administrativa de los ministerios y celebración de convenios de colaboración entre los ministerios y las empresas del Estado». En Derecho Administrativo Contemporáneo. Ponencias del II Congreso de Derecho Administrativo. Lima: Palestra Editores, 2006, p. 798.

2 Morón Urbina, Juan Carlos. Comentarios a la nueva Ley del Procedimiento Administrativo General. Lima: Gaceta Jurídica Editores, 2001, p. 222.

3 «Artículo I.- Ámbito de aplicación de la ley. La presente Ley será de aplicación para todas las entidades de la Administración Pública. Para los fines de la presente Ley, se entenderá por "entidad" o "entidades" de la Administración Pública: el Poder Ejecutivo, incluyendo Ministerios y Organismos Públicos Descentralizados; el Poder Legislativo; el Poder Judicial; los Gobiernos Regionales; los Gobiernos Locales; los Organismos a los que la Constitución Política del Perú y las leyes confieren autonomía; las demás entidades y organismos, proyectos y programas del Estado, cuyas actividades se realizan en virtud de potestades administrativas y, por tanto se consideran sujetas a las normas comunes de derecho público, salvo mandato expreso de ley que las refiera a otro régimen; y las personas jurídicas bajo el régimen privado que prestan servicios públicos o ejercen función administrativa, en virtud de concesión, delegación o autorización del Estado, conforme a la normativa de la materia [...]".

4 SANTAMARÍA PAStOR, Juan Alfonso. Principios de Derecho administrativo. Volumen I. Tercera edición. Madrid: Centro de Estudios Ramón Areces, 2000, p. 441.

REFORMAS A LOS MECANISMOS DE COLABORACIÓN

ADMINISTRATIVA A PROPÓSITO DE LOS DIEZ AÑOS DE VIGENCIA DE LA LEY 27444

REFORMS OF ADMINISTRATIVE COOPERATION MECHANISMS WITH REGARDTO THE TEN YEAR LIFE OF THE LAW 27444 
[...] con la distribución de funciones y potestades entre las administraciones públicas y los órganos que las componen se cubre una primera y muy importante etapa en el proceso de estructuración del sistema administrativo. Pero esta distribución funcional origina problemas característicos, como es la tendencia a la actuación independiente y descoordinada de cada una de las unidades, consecuencia de la hipervaloración del propio trabajo y de los intereses cuya satisfacción se les encomienda.

En la búsqueda de otorgarle coherencia a la actuación administrativa, un principio adicional que se desprende de la colaboración administrativa es el principio de coordinación, el cual, según López Olvera 5 , busca evitar la duplicidad de funciones estableciendo reglas y vínculos de coordinación entre las entidades, a fin de alcanzar la coherencia en la actuación de la administración pública.

Los principios antes enunciados, según Ivanega ${ }^{6}$, buscan corregir las disfunciones del modelo burocrático centralizado que perjudican las funciones del Estado. Asimismo, de acuerdo con dicha autora, se afirma que estos persiguen la coherencia en la actuación de las entidades administrativas, con lo que evitan contradicciones y disfunciones que entorpecerían la actuación administrativa.

\section{I.1. Análisis del artículo 76 de la LPAG}

Ahora bien, es oportuno analizar el artículo 76 de la LPAG 7 , el cual, en términos generales, reconoce el principio de colaboración, al señalar que se trata de un criterio mediante el que todas las entidades de la administración pública deben cooperar entre sí para el adecuado cumplimiento de sus funciones, sin mayor limitación que lo establecido por la Constitución o por la ley.

5 LÓPEZ OlverA, Miguel Alejandro. Los principios del procedimiento administrativo. En: http://www. bibliojuridica.org/libros/4/1594/12.pdf, revisado el 20 de agosto de 2011, p. 197.

6 IVANEGA, Miriam. Los principios de la organización administrativa. Buenos Aires: Ábaco de Rodolfo Depalma, 2005, pp. 175-177.

7 «Artículo 76.- Colaboración entre entidades. 76.1. Las relaciones entre las entidades se rigen por el criterio de colaboración, sin que ello importe renuncia a la competencia propia señalada por ley. 76.2. En atención al criterio de colaboración las entidades deben: 76.2.1. Respetar el ejercicio de competencia de otras entidades, sin cuestionamientos fuera de los niveles institucionales. 76.2.2. Proporcionar directamente los datos e información que posean, sea cual fuere su naturaleza jurídica o posición institucional, a través de cualquier medio, sin más limitación que la establecida por la Constitución o la ley, para lo cual se propenderá a la interconexión de equipos de procesamiento electrónico de información, u otros medios similares. 76.2.3. Prestar en el ámbito propio la cooperación y asistencia activa que otras entidades puedan necesitar para el cumplimiento de sus propias funciones, salvo que les ocasione gastos elevados o ponga en peligro el cumplimiento de sus propias funciones. 76.2.4. Facilitar a las entidades los medios de prueba que se encuentren en su poder, cuando les sean solicitados para el mejor cumplimiento de sus deberes, salvo disposición legal en contrario. 76.3. En los procedimientos sujetos a silencio administrativo positivo el plazo para resolver quedará suspendido cuando una entidad requiera la colaboración de otra para que le proporcione la información prevista en los numerales 76.2.3 y 76.2.4, siempre que esta sea indispensable para la resolución del procedimiento administrativo. El plazo de suspensión no podrá exceder el plazo dispuesto en el numeral 3 del artículo 132 de la presente Ley. 76.4. Cuando una entidad solicite la colaboración de otra entidad deberá notificar al administrado dentro de los 3 días siguientes de requerida la información [...]". 
Cabe señalar que este principio cuenta con respaldo constitucional, pues el Tribunal Constitucional, en la sentencia recaída en el expediente 004-2004-CC/TC ${ }^{8}$, ha establecido que el principio de colaboración se encuentraimplícitoen nuestroordenamientojurídico como una derivación del equilibrio de poderes reconocido en el modelo constitucional en los siguientes términos:

[...] 24. Sin embargo, la separación de poderes que configura nuestra Constitución no es absoluta, porque de la estructura y funciones de los Poderes delEstado regulados por la Norma Suprema, también se desprende el principio de colaboración de poderes. Al respecto, encontramos una colaboración de poderes cuando el artículo $104 .^{\circ}$ de la Constitución establece que el Congreso puede delegar en el Poder Ejecutivo la facultad de legislar, mediante decretos legislativos, sobre materia específica y por el plazo determinado establecidos en la ley autoritativa.

En este sentido, el artículo 76 regula dos aspectos de la colaboración administrativa. El primero, correspondiente a los numerales 76.1 y 76.2 de la LPAG, los cuales presentan el principio o criterio de colaboración entre entidades. Y el segundo, correspondiente a los numerales $76.3 \mathrm{y}$ 76.4 de la misma LPAG, los cuales enfocan este principio como una herramienta en el marco del procedimiento administrativo que serviría para resolver de una manera más ágil el procedimiento o para llegar a la verdad material antes de tomar una decisión.

Con relación al artículo 76.2 y sus incisos, cabe preguntarse por el límite para que las entidades del Estado puedan facilitar información, bienes y/o servicios, al amparo de los numerales 76.2.1, 76.2.2 y 76.2.3 de la LPAG. Sobre esto, citamos:

\section{[...] Artículo 76. - Colaboración entre entidades [...]}

76.2 En atención al criterio de colaboración las entidades deben:

76.2.1 Respetar el ejercicio de competencia de otras entidades, sin cuestionamientos fuera de los niveles institucionales.

76.2.2 Proporcionar directamente los datos e información que posean, sea cual fuere su naturaleza jurídica o posición institucional, a través de cualquier medio, sin más limitación que la establecida por la Constitución o la ley, para lo cual se propenderá a la interconexión de equipos de procesamiento electrónico de información, u otros medios similares.

76.2.3 Prestar en el ámbito propio la cooperación y asistencia activa que otras entidades puedan necesitar para el cumplimiento de sus propias

8 Sentencia del Tribunal Constitucional recaída en el expediente 004-2004-CC, de fecha 31 de diciembre de 2004, sobre el proceso de conflicto de competencia seguido por el Poder Judicial contra el Poder Ejecutivo. En http://www.tc.gob.pe/jurisprudencia/2005/00004-2004-CC.html, revisado el 20 de agosto de 2011. 
funciones, salvo que les ocasione gastos elevados o ponga en peligro el cumplimiento de sus propias funciones.

76.2.4 Facilitar a las entidades los medios de prueba que se encuentren en su poder, cuando les sean solicitados para el mejor cumplimiento de sus deberes, salvo disposición legal en contrario [...]

Los citados preceptos legales regulan los deberes que deben asumir las entidades que forman parte de la administración en el marco de la colaboración administrativa. En tal sentido, y tal como se puede apreciar del tenor de los referidos numerales, el deber de colaboración solo podría ejercerse en función de «las competencias de otras entidades» o del «cumplimiento de sus propias funciones».

Es importante tener en cuenta que las solicitudes e incluso aquellos acuerdos de colaboración deben tener algunos límites, derivados de los alcances del artículo 76 de la LPAG, por lo que deben ser sometidos a las condiciones que explicamos a continuación ${ }^{9}$.

Debe tratarse de un pedido fundado en el ejercicio de las legítimas competencias de la autoridad solicitante. Esto es claro, y debería constituir la primera condición para el ejercicio de la colaboración administrativa, dado que, por el principio de legalidad, ninguna entidad de la administración pública puede actuar fuera del marco establecido por la ley.

Es así que el artículo 78.1 de la LPAG establece que «la procedencia de la colaboración solicitada es regulada conforme a las normas propias de la autoridad solicitante [...]», en clara referencia al margen de las competencias que una entidad está obligada a respetar.

En tal sentido, para la procedencia de un pedido de parte de una entidad a otra, la autoridad solicitante debe motivar su pedido en la necesidad que tiene de la información solicitada para poder cumplir con el ejercicio de sus funciones asignadas, y debe observar estrictamente las funciones y competencias de la entidad solicitada.

Por ello, no son admisibles aquellos pedidos que se motiven en razones personales de las autoridades o funcionarios de las entidades, sino que deben aceptarse únicamente las solicitudes institucionales que detallen exactamente la información requerida para el cumplimiento o para la ejecución de las funciones institucionales de cada entidad. Ahora bien, ello no supone que el cumplimiento del pedido sea discrecional, puesto que siempre será reglado, tal como se indica en el artículo 78.1 de la LPAG, cuando se precisa que el cumplimiento de la colaboración solicitada es regido por las normas propias de la autoridad solicitada. 
En tal sentido, flexibilizando el marco jurídico de actuación de los pedidos, estos deben ser motivados en el cumplimiento de las funciones de las entidades, pero sometidos a ciertas reglas.

El pedido debe encontrarse en la posibilidad de ser satisfecho mediante el ejercicio de las funciones ordinarias de la entidad requerida. El pedido de colaboración debe estar orientado a la satisfacción de las tareas o funciones que la entidad requerida tiene asignada y no debe incluir operaciones o actividades ajenas a la misma. No cabe efectuar habilitaciones genéricas o realizar pedidos de tipo general. Se trata de tareas que no excedan de sobremanera las funciones ordinarias de la entidad requerida y que no afecten el contenido del deber general de actuación.

La solicitud de la entidad requirente no debe causar perjuicio al servicio de los intereses que tiene la entidad o al cumplimiento normal de sus funciones. Esto es claro, los pedidos de colaboración, no pueden causar perjuicio al servicio de los intereses generales que tiene la entidad para el normal cumplimiento de sus funciones.

A partir de las premisas expuestas, no puede considerarse que las partes involucradas en la ejecución las actividades o acciones de colaboración puedan descuidar el ejercicio de sus funciones por tratar de cumplir con las solicitudes requeridas por las entidades públicas.

En este sentido, se deben implementar a nivel interno de cada entidad las medidas necesarias para que el deber de colaboración entre entidades públicas sea ejercido racionalmente y no termine por sobrecargar los costos y la actividad normal de las entidades.

\subsection{Análisis del artículo 77 de la LPAG}

Una vez identificadas las reglas mediante las cuales se puede y se debe colaborar entre entidades, el artículo 77 de la LPAG $^{10}$ expone los medios que materializan el ejercicio de la colaboración administrativa.

De este modo, se entiende que las entidades pueden otorgar estabilidad a la colaboración interinstitucional mediante los mecanismos que explicamos a continuación.

10 «Artículo 77.- Medios de colaboración interinstitucional. 77.1. Las entidades están facultadas para dar estabilidad a la colaboración interinstitucional mediante conferencias entre entidades vinculadas, convenios de colaboración u otros medios legalmente admisibles. 77.2. Las conferencias entre entidades vinculadas permiten a aquellas entidades que correspondan a una misma problemática administrativa, reunirse para intercambiar mecanismos de solución, propiciar la colaboración institucional en aspectos comunes específicos y constituir instancias de cooperación bilateral. Los acuerdos serán formalizados cuando ello lo amerite, mediante acuerdos suscritos por los representantes autorizados. 77.3. Por los convenios de colaboración, las entidades a través de sus representantes autorizados, celebran dentro de la ley acuerdos en el ámbito de su respectiva competencia, de naturaleza obligatoria para las partes y con cláusula expresa de libre adhesión y separación [...]".

REFORMAS A LOS MECANISMOS DE COLABORACIÓN

ADMINISTRATIVA A PROPÓSITO DE LOS DIEZ AÑOS DE VIGENCIA DE LA LEY 27444

REFORMS OF ADMINISTRATIVE COOPERATION MECHANISMS WITH REGARDTO THE TEN YEAR LIFE OF THE LAW 27444 
Por un lado, pueden ser conferencias utilizadas para reunir a dos o más entidades que busquen solucionar una misma problemática, mediante la colaboración institucional en aspectos específicos o a través de la constitución de instancias de cooperación bilateral. Asimismo, estas conferencias podrán dar lugar a acuerdos que deberán formalizarse mediante los denominados convenios de colaboración.

Luego están los convenios de colaboración, los cuales son la formalización de los acuerdos que, a su vez, son producto de las conferencias u otros medios suscritos por los representantes autorizados o con competencia para ello.

La utilización de una figura como la del convenio permite una activa interacción entre las entidades, lo que supone el intercambio de información, beneficios y trabajo conjunto para el mejor logro de sus fines. Ahora bien, el empleo de esta figura no puede ser lesivo a la igualdad existente entre las partes, puesto que la figura del convenio de colaboración puede considerarse como una suerte de acuerdo de trato preferente enmarcado en los alcances de los principios de lealtad institucional y de colaboración, pero no puede consagrar conductas o políticas discriminatorias.

Otros medios legalmente admisibles se refieren a aquellos medios que coadyuven a la solución de problemas de dos o más entidades, y que no necesariamente coincidan con uno de los anteriormente mencionados.

\section{I.3. Análisis del artículo 78 de la LPAG}

El artículo 78 de la $\mathrm{LPAG}^{11}$, bajo la denominación de «ejecución de la colaboración entre autoridades», regula por el lado del numeral 78.1 un conjunto de reglas procedimentales que deben ser observadas y cumplidas por las entidades solicitantes y solicitadas para efectos de llevar a cabo una modalidad de colaboración administrativa.

En este sentido, se puede afirmar que los pedidos de colaboración deben encontrarse acorde, no solo al ordenamiento jurídico, sino también a las normas de organización y funciones, directivas y demás instrumentos de gestión internos de la entidad solicitada. Asimismo, la entidad solicitada o requerida deberá cumplir y ejecutar el pedido de colaboración dentro del margen de sus propias normas internas.

Por su parte, el numeral 78.2 de la LPAG establece reglas de responsabilidad para las autoridades administrativas en el marco de la colaboración

11 «Artículo 78.- Ejecución de la colaboración entre autoridades. 78.1. La procedencia de la colaboración solicitada es regulada conforme a las normas propias de la autoridad solicitante, pero su cumplimiento es regido por las normas propias de la autoridad solicitada. 78.2. La autoridad solicitante de la colaboración responde exclusivamente por la legalidad de lo solicitado y por el empleo de sus resultados. La autoridad solicitada responde de la ejecución de la colaboración efectuada [...]». 
entre entidades, donde se puede apreciar que se deja de lado la alusión a «entidad» para atribuir responsabilidad a las «autoridades», la cuales, en rigor, son las que llevarán a cabo y ejecutarán el objeto del pedido de colaboración.

En este aspecto, se puede advertir un detalle que no puede ser pasado por alto. Por un lado, se establece que la autoridad solicitante responderá por la legalidad del pedido y por el empleo que otorgue al resultado de la colaboración. En rigor y a la luz de los alcances de la petición y de la naturaleza de los convenios de colaboración, ello no debería dar lugar, a entender que, ante un pedido ilegal, solo responde la autoridad solicitante, sino también la autoridad solicitada, dado que se encuentra en su potestad realizar o no algo ilegal, por tanto la regla de responsabilidad por ilegalidad del pedido se extiende tanto para la autoridad solicitante como para la autoridad solicitada.

\section{I.4. Análisis del artículo 79 de la LPAG}

El artículo 79 de la LAPG ${ }^{12}$ finalmente dispone que el deber de colaboración entre entidades, por regla general, no implica el pago de tasas, derechos o algún otro concepto que genere un pago entre entidades, puesto que el deber de colaboración se rige por un principio de gratui$\operatorname{dad}^{13} \mathrm{y}$ no tendría sentido admitir que el Estado se pague a sí mismo ${ }^{14}$.

Ello se sustenta, según Morón, «de un lado, que el presupuesto público es quien en verdad da sustento a los gastos de las actividades de colaboración y del otro que en cierta medida, la prestación gratuita solo opera como un mecanismo de redistribución del erario nacional, en aras del logro de la finalidad pública» ${ }^{15}$. En tal sentido, en la medida que la información solicitada sea producida por la entidad a quien se le solicita, en el ejercicio ordinario de sus funciones, no procede el pago de tasa administrativa alguna.

Sin embargo, el numeral 79.2 admite como excepción la posibilidad de que puedan existir supuestos específicos en los cuales sí se genere la obligación de pagar los gastos efectivos realizados, pero solo cuando la actividad requerida a la autoridad solicitada se encuentre fuera del ámbito de las actividades ordinarias de la entidad.

12 «Artículo 79.- Costas de la colaboración. 79.1. La solicitud de colaboración no genera el pago de tasas, derechos administrativos o de cualquier otro concepto que implique pago alguno, entre entidades de la administración pública. 79.2. A petición de la autoridad solicitada, la autoridad solicitante de otra entidad tendrá que pagar a esta los gastos efectivos realizados cuando las acciones se encuentren fuera del ámbito de actividad ordinaria de la entidad [...]».

13 MelgaREJO DÁVILA, Rafael. «Los sujetos del procedimiento administrativo». En Sobre la Ley del Procedimiento Administrativo General. Lima: UPC, 2009, p. 283.

14 Morón URBINA, Juan Carlos. Ob. cit., p. 225.

15 lbíd., p. 225.

REFORMAS A LOS

MECANISMOSDE COLABORACIÓN

ADMINISTRATIVA A PROPÓSITO DE LOS DIEZ AÑOS DEVIGENCIA DE LA LEY 27444

REFORMS OF ADMINISTRATIVE COOPERATION MECHANISMS WITH REGARDTO THETEN YEAR LIFE OF THE LAW 27444 
Ello quiere decir que corresponde el pago por parte de la autoridad solicitante de los gastos efectivos solo cuando el objeto de la colaboración «se encuentre fuera del ámbito de una actividad ordinaria» de la autoridad solicitada, es decir cuando se trate de una actividad extraordinaria.

Ahora bien, iqué se debe entender por el desarrollo de una actividad extraordinaria de parte de una entidad requirente? La respuesta no es sencilla y puede dar lugar, a una serie de alternativas en función de la naturaleza del pedido formulado por la entidad solicitante. En realidad, una serie de actividades podrían calificar como extraordinarias. Sin embargo, dependiendo del caso en concreto, se deberá realizar un análisis y balance de las actividades de una entidad para efectos de si estas califican como tales. Asimismo, bajo una rigurosa justificación de los gastos efectivamente realizados, se procederá a pagar a la autoridad solicitada los mayores gastos que el pedido ocasione, sin embargo, ello debe conducir a una actitud razonable de ambas partes, pues se entiende que ninguna de ellas, en el ejercicio del derecho-deber de colaboración, puede motivar su actuación por un interés lucrativo respecto de la actuación de la contraparte.

En el contexto descrito, la colaboración administrativa no puede ser desnaturalizada por la asunción unilateral de gastos. Para tal efecto, es clave determinar los límites y alcances del término «gastos efectivos».

En primer lugar, debe analizarse los alcances de los componentes del precio o de la tasa que resulte aplicable al caso. De un lado, para formar un precio debe establecerse los componentes del costo y los componentes de la utilidad esperada. En este sentido, el término «gastos efectivos» se traduce justamente en los costos efectivos en que ha incurrido la entidad a la que se le solicita la colaboración, y que esta no haya sido producida mediante el ejercicio de su actividad ordinaria.

Debe tenerse en cuenta que el artículo 79.2 de la LPAG regula los supuestos del cumplimiento del deber de asistencia activa. Tal como se ha indicado, el deber de asistencia se refiere a los términos del artículo 76.2.3 de la LPAG, norma directamente vinculada a la actividad de relación de las entidades públicas consistente en «prestar en el ámbito propio la cooperación y asistencia activa que otras entidades puedan necesitar para el cumplimiento de sus propias funciones, salvo que les ocasione gastos elevados o ponga en peligro el cumplimiento de sus propias funciones».

En términos formales, el cumplimiento del deber de colaboración de acuerdo a los alcances del artículo 76.2.2 no debe generar mayores gastos. Ahora bien, si es que se solicita dicha colaboración, fuera del ámbito ordinario de las actividades a cargo de la entidad, ello puede implicar que dicha entidad requerida o solicitada se encuentre en la obligación 
ineludible de colaborar, pero los gastos efectivos en los que se incurra para materializar dicha colaboración deben ser expresamente establecidos.

Finalmente, para concluir con este punto, cabe señalar que los sujetos que participan del principio de colaboración están compuesto por diversas entidades públicas y empresas que se encuentran adscritas a un sector de la actividad estatal. En base a ello se celebran convenios entre entidades públicas. En nuestra opinión, esto refleja una situación fáctica compleja, pues existen supuestos en los que las entidades públicas pueden, bajo pretexto de colaboración administrativa, prestar servicios complementarios o extraordinarios, distintos de su actividad ordinaria, y de los cuales obtener beneficios lucrativos.

\section{II.LA NECESIDAD DE UN NUEVO ENFOQUE DE LA COLABORACIÓN ADMINISTRATIVA}

Una vez analizado el marco legal de la colaboración administrativa en la LPAG se puede llegar preliminarmente a tres conclusiones:

- La LPAG solo se limita a regular los supuestos de colaboración entre entidades como la única forma de colaboración administrativa que pudiera existir en el ordenamiento jurídico, y obvia el deber de colaboración que trasciende únicamente a las entidades administrativas.

- La LPAG, de manera similar a la Ley del Régimen Jurídico de las Administraciones Públicas y Procedimiento Administrativo Común de España, crea un marco jurídico con reglas para la colaboración entre entidades. No obstante, no toma en cuenta que la ley española enfoca la colaboración administrativa, los convenios y las conferencias como reglas generales, que responden a diversas técnicas de cooperación ampliamente reconocidas por la doctrina administrativa ${ }^{16}$ y clasificadas como orgánicas y funcionales.

- Si bien el marco legal establecido en la LPAG no señala que los convenios de colaboración administrativa sean los únicos medios por los cuales se formaliza la colaboración administrativa, se debe tener en cuenta que las conferencias u otros mecanismos de colaboración apuntan a la celebración de convenios. Esto restringe la posibilidad de que existan otras formas de colaboración que no se limitan a la celebración de convenios.

REFORMAS A LOS MECANISMOS DE COLABORACIÓN

ADMINISTRATIVA A PROPÓSITO DE LOS DIEZ AÑOS DEVIGENCIA DE LA LEY 27444

REFORMS OF ADMINISTRATIVE COOPERATION MECHANISMS WITH REGARDTO THE TEN YEAR LIFE OF THE LAW 27444 
En función de lo anteriormente descrito, el nuevo enfoque que se busca plantear para la colaboración administrativa en el Perú se podría explicar de una forma más proactiva, si se toma como referencia las técnicas de cooperación y de organización utilizadas en el ordenamiento español, y que son aplicadas de acuerdo a la realidad de nuestra administración pública en lo que sea pertinente, a fin de tener claro el panorama de la colaboración y de no restringir su ámbito de aplicación.

De este modo, según Santamaría Pastor, las técnicas de cooperación y coordinación responden a un solo objetivo, que es lograr la coherencia de la actuación de la administración pública, lo que vendría a ser, en nuestro ordenamiento, los principios de unidad en la actuación de la administrativa —coherencia y colaboración — establecidos en el artículo 76 de la LPAG.

En tal sentido, las técnicas de cooperación existentes entre las distintas entidades de la administración pública sirven para ilustrar e identificar las distintas formas de cooperación existente entre las entidades que forman parte de la administración pública. Estas son las siguientes:

- Técnicas orgánicas. Son aquellas empleadas para la gestión de la participación de los representantes de las distintas entidades administrativas en la toma de decisiones estatales, o bien aquellas empleadas a través de órganos de cooperación, consulta y colaboración. Un ejemplo de estas técnicas son las denominadas conferencias sectoriales, novedad introducida en el artículo 77 de la LPAG. El empleo de estas técnicas orgánicas se relaciona con la idea de la participación conjunta o la concertación de la actuación de las distintas unidades orgánicas de la administración pública en los procesos de gestión de los asuntos públicos. Otro ejemplo podría ser la constitución de comisiones multisectoriales cuya finalidad es solucionar un problema o atender un asunto de manera inmediata - por tanto de naturaleza temporal—y que requiere de la participación de uno o más representantes de los distintos ministerios que forman parte de la estructura del Estado.

- Técnicas funcionales. También denominadas técnicas de carácter procedimenta ${ }^{17}$, nos remiten al ejercicio de funciones administrativas, toda vez que existe una entidad que solicita colaboración de otra para que esta, en el ejercicio de sus funciones o actividades ordinarias, le brinde el soporte y apoyo necesario para el cumplimiento de las suyas. Según Santamaría Pastor, 
se reconocen cinco formas de cooperación mediante técnicas funcionales ${ }^{18}$ :

[...] a) El deber general de información. - Deber que señala a las entidades de la Administración Pública a facilitarse entre sí, la información que precisen sobre la actividad que desarrollen en el ejercicio de sus propias competencias, con la finalidad, por ejemplo de recabar medios probatorios. Este deber, en la LPAG ha sido inspirado por los literales «C» y «e» del artículo 4º de la Ley 30/1992, Ley del Régimen Jurídico de las Administraciones Públicas y del Procedimiento Administrativo Común de España, que nos indica: Artículo $4^{\circ}$. - Principios de las relaciones entre las Administraciones Públicas. - Las Administraciones Públicas actúan y se relacionan de acuerdo con el principio de lealtad institucional y, en consecuencia, deberán: [...] facilitar a las otras Administraciones la información que precisen sobre la actividad que desarrollen en el ejercicio de sus propias competencias [...] A efectos de lo dispuesto en las letras c) y d) del apartado anterior, las Administraciones públicas podrán solicitar cuantos datos, documentos o medios probatorios se hallen a disposición del ente al que se dirija la solicitud. Podrán también solicitar asistencia para la ejecución de sus competencias [...]

De este modo, se entiende que la asistencia y cooperación requerida en lo que se refiere a entregar información, solo podrá negarse cuando el ente del que se solicita no esté facultado para prestarla, no disponga de medios suficientes para ello o cuando, de hacerlo, causara un perjuicio grave a los intereses cuya tutela tiene encomendada o al cumplimiento de sus propias funciones [...]

b) El deber de asistencia. - Este deber señala la obligación de las entidades administrativas de prestar, en el ámbito de sus propias competencias, la cooperación y asistencia activa que otras entidades administrativas pudieran requerir ${ }^{19}$. Esta técnica, según González Pérez, remite a la existencia del denominado auxilio administrativo ${ }^{20}$, esto es, el deber general de los órganos administrativos de prestarse mutua ayuda y colaboración. Esta figura encuentra su correlato en el denominado «deber de auxilio judicial», que existe entre los jueces y tribunales como la obligación de ayudarse y auxiliarse mutua y recíprocamente.

En este sentido, se debe entender que esta técnica constituye una expresión del principio por el cual «toda autoridad debe prestar auxilio complementario a otras autoridades a solicitud de estas».

c) Las técnicas de participación en procedimientos conjuntos. - Se trata de la participación de una entidad en procedimientos que tramita

REFORMAS A LOS

MECANISMOS DE COLABORACIÓN

ADMINISTRATIVA A PROPÓSITO DE LOS DIEZ AÑOS DEVIGENCIA DE LA LEY 27444

REFORMS OF ADMINISTRATIVE COOPERATION MECHANISMS WITH REGARDTO THE TEN YEAR LIFE OF THE LAW 27444 
y resuelve otro distinto. Esta intervención suele tener lugar por vía de aprobación, propuesta o informe previo a la toma de decisión. Esta técnica de colaboración funcional puede ser ejemplificada de distintas formas, dado que es muy común en la Administración Pública se requiera la opinión previa, informe previo u otras consideraciones previas a la toma de decisiones, en el marco de procedimientos administrativos. Por ejemplo, en INDECOPI se llevan a cabo procedimientos trilaterales sancionadores y no sancionadores. Un ejemplo de estos procedimientos trilaterales sancionadores es el «procedimiento administrativo sancionador sobre conductas anticompetitivas» ${ }^{21}$, que en el marco del Decreto Legislativo $\mathrm{N}^{\circ} 1034$, se inicia siempre de oficio o por iniciativa de la Secretaría Técnica de la Comisión de Defensa de la Libre Competencia o por denuncia de parte. Este tipo de procedimiento administrativo sancionador requiere durante sus etapas, en numerosas oportunidades, que la Secretaría Técnica de la Comisión de Libre Competencia realice actuaciones previas para recabar medios probatorios, los que a su vez, servirán para tomar una decisión sobre el caso en controversia. Estas actuaciones, según CIERCO SEIRA ${ }^{22}$ forman parte de la facultad discrecional de la administración, dentro de los márgenes legales, de realizar las actuaciones procedimentales necesarias en cada caso para preparar la adopción de una decisión.

De este modo, tal como sucedió en el caso CIVA vs CIAL, recaído en el Expediente $\mathrm{N}^{\circ}$ 024-2004/TDC-INDECOPI ${ }^{23}$, el INDECOPI tuvo que pedir cierta información relevante al Ministerio de Transportes y Comunicaciones, a fin de lograr resolver el caso. En este sentido, resulta evidente que el MTC tuvo participación en el referido procedimiento trilateral sancionador para la resolución del caso, dado que de lo contrario, INDECOPI no habría podido recabar todas las pruebas. Por tanto, es importante indicar que el deber de colaboración en el procedimiento administrativo debe realizarse, no solo bajo el principio de colaboración, sino también bajo los principios de celeridad, verdad material y eficiencia.

Por otro lado, INDECOPI también lleva a cabo procedimientos trilaterales no sancionadores, como es el caso del procedimiento de autorización previa de operaciones de concentración empresarial en el sector eléctrico, el cual involucra a dichas empresas para poder fusionarse o reorganizarse. Este tipo de procedimientos, que no culmina con una sanción a las partes del mismo, termina con la emisión de una autorización. En este sentido, la Comisión de Defensa de la Libre Competencia

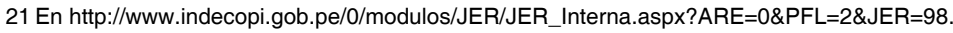

22 CIERCO SEIRA, César. La participación de los interesados en el procedimiento administrativo. Zaragoza: Publicaciones del Real Colegio de España Bolonia, 2002, p. 71.

23 Resolución 0493-2004/TDC-INDECOPI de INDECOPI, recaída en el expediente 024-2004/CCD, de fecha 22 de setiembre de 2004, sobre el procedimiento seguido por Turismo Civa S.A.C. contra Expreso Cial S.A.C. por la presunta comisión de actos de competencia desleal. En http://www. indecopi.gob.pe/0/modulos/JER/JER_Interna.aspx?ARE=0\&PFL=2\&JER=99. 
de INDECOPI para poder motivar sus decisiones, podrá recabar los datos del Ministerio de Energía y Minas o, según sea el caso de OSINERGMIN. Por tanto, en este tipo de procedimientos, también corresponde hablar de colaboración administrativa en el procedimiento.

d) Las técnicas de planificación conjunta. - Supone la elaboración de planes o programas referidos a materias, obras o servicios de interés común, que se financian por todos o parte de los entes interesados en ellos, según los casos.

En el Perú, el Centro Nacional de Planeamiento Estratégico - CEPLAN tiene como misión Impulsar la instauración de una cultura de planeamiento estratégico concertado en los diferentes niveles de gobierno, asegurando que las acciones del Estado alcancen los objetivos nacionales de desarrollo e integración a la economía global y la mejora de la gestión pública.

$\mathrm{Al}$ respecto, cabe señalar que la técnica de planificación requiere ineludiblemente de acciones de concertación y colaboración entre las entidades de la Administración Pública, dado que el cumplimiento de un plan estratégico requiere ineludiblemente de la participación de todas las entidades en conjunto.

e) Los convenios entre entidades públicas. - Tal como se señaló en párrafos anteriores, esta es la técnica por excelencia de la colaboración administrativa, dado que es más usual y es considerada por Santamaría Pastor como la más importante y frecuente.

Los convenios de colaboración pueden adoptar innumerables denominaciones, no obstante, en rigor son un mecanismo adicional de colaboración. Culminado el análisis de las técnicas de colaboración administrativa, es importante señalar que todas las técnicas de colaboración buscan que, de manera coordinada y coherente se logre la unidad de actuación de la misma. Asimismo, es importante destacar que las mencionadas técnicas no hacen más que abrir el panorama de la colaboración administrativa, incluso más allá del concebido y regulado en la LPAG, esto es se toma en consideración que la colaboración no se restringe a la celebración de convenios o conferencias, sino que esta tiene un campo mucho más amplio de acción.

De este modo, la colaboración administrativa debe ser vista como un fenómeno general cuyo ámbito de aplicación no se agota en la colaboración entre entidades, sino también incluso entre entidades públicas y privadas; $y$, asimismo, entre entidades y personas naturales [...] (las cursivas son nuestras).

\section{II.1. Un fenómeno general}

La colaboración administrativa debe ser apreciada como un fenómeno general, pues se refiere a una visión mucho más amplia a la concebida

REFORMAS A LOS MECANISMOS DE COLABORACIÓN

ADMINISTRATIVA A PROPÓSITO DE LOS DIEZ AÑOS DE VIGENCIA DE LA LEY 27444

REFORMS OF ADMINISTRATIVE COOPERATION MECHANISMS WITH REGARDTO THE TEN YEAR LIFE OF THE LAW 27444 
por la LPAG. Sin embargo, en el esquema adoptado por la actual normativa recogida en la LPAG existe un criterio restrictivo de aplicación, que la extiende únicamente al caso de las entidades públicas señaladas en el propio ámbito de aplicación de la ley 27444.

En otras palabras, los principios de colaboración y de asistencia no solo deben vincularse a los mecanismos que activan entre sí las propias entidades públicas, sino también a entidades privadas e incluso personas naturales que tengan un rol en una determinada situación jurídica, como lo es, por ejemplo, el procedimiento administrativo.

\subsection{Modalidades de colaboración administrativa}

De acuerdo a la nueva perspectiva planteada con respecto a la colaboración administrativa, se pueden distinguir dos modalidades de este tipo de actuación - las que, a su vez, deberían contar con un marco normativo-, a fin de poder contribuir con la coherencia y unidad de la actuación administrativa:

\section{II.2.1. Entre entidades públicas y privadas}

El viejo concepto de colaboración entre entidades pierde de vista que el mayor aliado del Estado y de la administración pública, para que esta pueda cumplir las funciones de interés público que le encomienda la Constitución y las leyes, es la empresa privada. A diferencia de lo que ocurría en el pasado, hoy en día son frecuentes los casos en que se presenta una activa interacción entre las entidades particulares y los agentes privados, en los cuales no siempre se actúan por estrictos criterios de utilidad o lucro, sino también, con el propósito de colaborar entre sí, o en la mayoría de los casos, colaborar a favor del Estado.

Por ejemplo, uno de los más importantes ejemplos de colaboración administrativa - y de gran repercusión en la economía de un país - son las asociaciones público-privadas, las concesiones y demás formas asociativas entre el Estado y la empresa privada, que tienen como principal finalidad la ejecución de proyectos de obras e infraestructura, los que a su vez satisfacen intereses y necesidades públicas.

\section{II.2.2. Entre particulares}

Otra modalidad de colaboración que no debe pasarse por alto es la de los particulares para con la administración pública, en la medida que estos son sujetos dentro del procedimiento administrativo y tienen el deber de actuar de buena fe, según el principio de conducta procedimental establecido en el numeral 1.8 del numeral I del título preliminar de la LPAG.

Un claro ejemplo de colaboración entre los particulares y las entidades públicas se presenta en materia tributaria, cuando los contribuyentes 
están en la obligación de colaborar con la administración tributaria, a efectos de cumplir sus obligaciones tributarias en los montos y plazos establecidos por la ley.

\section{II.3. Características}

REFORMAS A LOS MECANISMOS DE

En función de lo expuesto hasta este punto, el nuevo panorama de la colaboración administrativa requiere identificar que posee dos principales características.

\section{II.3.1. Sustancial}

En tanto la colaboración administrativa responde al deber general de colaboración en la administración pública y sobre todo a los principios de unidad y coherencia de su actuación.

De este modo, la perspectiva sustancial de la colaboración administrativa invoca a reconocerla como una herramienta útil para lograr la unidad y coherencia en la actuación administrativa, que tiene como principal fundamento el deber de colaboración, asistencia o «auxilio», a fin de que la administración pueda cumplir adecuadamente y oportunamente las funciones de interés público que le han sido encomendadas por el ordenamiento jurídico.

\section{II.3.2. Procesal}

La colaboración administrativa, como toda herramienta que busca lograr las finalidades antes indicadas, debe poseer reglas adecuadas que faciliten su empleo y regulen supuestos de incumplimiento y solución de conflictos, dado que las reglas vigentes en la LPAG se reducen a ciertas modalidades de colaboración que contemplan una visión más amplia de la misma.

En este sentido, según la LPAG, la única regla que daría curso a un supuesto de colaboración administrativa es la referida a las normas aplicables a los pedidos de colaboración.

\section{LA NECESIDAD DE ACTUALIZAR LAS REGLAS VIGENTES}

Con relación al numeral 76.2 de la LPAG, que regula los deberes que deben cumplir las entidades en el marco del principio de colaboración, es importante tener en cuenta que los deberes que una entidad pueda asumir a partir de un compromiso de colaboración pueden desbordar a los estrictamente denominados en el referido numeral, por ello sería oportuno que en una eventual y futura revisión de la LPAG se añada un numeral que otorgue a las entidades un margen de discrecionalidad para establecer su actuación en el marco de la Constitución y la ley.

COLABORACIÓN

ADMINISTRATIVA

A PROPÓSITO DE

LOS DIEZ AÑOS

DE VIGENCIA DE

LA LEY 27444

REFORMS OF

ADMINISTRATIVE

COOPERATION

MECHANISMS

WITH REGARDTO

THE TEN YEAR LIFE

OFTHE LAW 27444 
Otro aspecto que debería ser modificado de la LPAG es el referido a la propia colaboración administrativa, dado que sería oportuno ampliar aún más el panorama que fue plasmado en la referida ley hace casi diez años. En tal sentido, se debería introducir las técnicas de colaboración, orgánicas y funcionales, a fin de otorgar realmente coherencia a la actuación administrativa.

Una vez adoptada la sugerencia anteriormente planteada, sería oportuno invocar la creación de normas procedimentales que logren dar cabida a las distintas formas de colaboración administrativa, e inclusive que eviten la obtención de ganancia o lucro, por parte de una entidad pública con respecto de otras. No han sido pocos los casos que a la luz de la experiencia de colaboración administrativa han significado por el carácter exclusivo o casi monopólico de una actividad de parte del Estado - RENIEC, SUNAT, SAT, SUNARP, etcétera- la existencia de mayores costos o similares a los de cualquier administrado para otras entidades públicas.

\section{CONCLUSIONES}

- A partir de la entrada en vigencia de la LPAG en el año 2001, ya no se concibe que las entidades de la administración pública se relacionan únicamente en la vía del conflicto, sino, más bien, se introduce una regla general de colaboración y cooperación entre las entidades.

- La aplicación de las reglas de colaboración administrativa, a la luz de los diez años de vigencia de la ley 27444, nos plantea la necesidad de efectuar algunos ajustes en función de las experiencias acumuladas en el marco de aplicación de la indicada ley, así como del nuevo rol que vienen asumiendo las entidades públicas en sus relaciones entre así, así con terceros.

- Las relaciones entre las entidades públicas deben ser eficaces y orientarse a la unidad y coherencia de la actuación del Estado. Siendo ello así, es necesario que se recurra las vías directas o internas de la administración pública antes que a formulas o soluciones externas que encarezcan la economía y la celeridad de la gestión pública. Por ello, las entidades deben recurrir a mecanismos de cooperación que les permitan intercambiar información y servicios mutuos.

- Las técnicas de cooperación orgánicas y funcionales no son técnicas propiamente aplicables al caso peruano, dado que estas responden, básicamente, a la realidad española. Sin embargo, de manera didáctica, se ilustró lo útil que puede ser comenzar 
a ponerlas en práctica en nuestro ordenamiento, a través de los órganos jurisdiccionales y el propio Tribunal Constitucional.

- Las técnicas de cooperación orgánicas están referidas a la participación de las entidades o de sus representantes en el manejo de las decisiones estatales o con respecto a la creación de órganos sectoriales que estén destinadas a una gestión pública concertada a nivel de las diversas autoridades competentes.

- Por otro lado, las técnicas de cooperación funcionales se refieren al ejercicio del deber de colaboración de las diferentes entidades de la administración pública, cuyo contenido indica que toda entidad pública debe brindar soporte y apoyo necesario para el cumplimiento de los fines de las entidades que se lo soliciten, siempre y cuando lo solicitado no exceda el ámbito de las funciones ordinarias de la entidad solicitada.

- La colaboración administrativa como un principio que no solo abarca a todas las entidades de la administración pública parte de comprender que la unidad y coherencia de la actuación administrativa no solo es responsabilidad de esta, sino también de las demás entidades con las que se pueda relacionar e incluso con las personas a título particular.

- Es indudable que la fotografía de la colaboración administrativa tomada el año 2001 requiere un nuevo análisis y una actualización del panorama, toda vez que, hoy por hoy, no se puede restringir la colaboración administrativa al deber de asistencia solo entre entidades o para la celebración de convenios de colaboración. 